\title{
Possible soil thermal response to seismic activities in Alborz region (Iran)
}

\author{
N. Rezapour ${ }^{1}$, M. Fattahi ${ }^{1,2}$, and A. A. Bidokhti ${ }^{1}$ \\ ${ }^{1}$ The Institute of Geophysics, The University of Tehran, North karegar St., Tehran, Iran \\ ${ }^{2}$ Oxford University Center of Environment South Parks Road,Oxford, OX1 3QY, UK
}

Received: 20 October 2009 - Revised: 22 February 2010 - Accepted: 24 February 2010 - Published: 15 March 2010

\begin{abstract}
In this investigation, relations between the ground's thermal properties and 70 earthquakes with a magnitude $>4$ Richter in the Alborz region during a period of 12 years (1992 to 2004) were studied. Typical changes of ground temperature, $0.4^{\circ} \mathrm{C}$; thermal diffusivity, $0.028 \mathrm{~m}^{2} \mathrm{~s}^{-1} \times 10^{-6}$ and ground heat flux take place a few hours prior to the earthquakes. The values of thermal diffusivity depend on the ground moisture content, which may change during seismic activities. The analysis of ground heat flux from the epicentre and it's surrounding regions show some anomalous behavior before the earthquakes but with different signs in the areas close to the sea and far away from the sea.

The changes of the ground's thermal properties prior to the earthquakes in the Alborz region are attributed to the increase in seismic activities in the epicentre and it's surrounding regions. The anomalous behavior in the ground thermal properties shows great potential in providing early warning of imminent earthquake.
\end{abstract}

\section{Introduction}

Although earthquake prediction is still a challenging effort, recent studies have suggested that numerous geophysical and ionospheric parameters are closely related to the earthquakes that have occurred throughout the world (Esposito et al., 2001; Hayakawa et al., 2004, 1994; Hayakawa, 1999; Pulinets, 2004; Shvets et al., 2004; Uyeda et al., 2000). These parameters could be potential precursors of earthquake if we fully understood their characteristic behavior (e.g. Dey and Singh, 2003). Meteorological parameters presented in this essay could be precursors for tectonic activities.

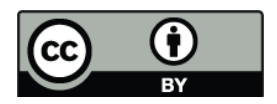

Correspondence to: N. Rezapour (rezapour@irimo.ir)
Some changes in thermal parameters have been observed prior to earthquakes (Cervone et al., 2005; Day et al, 2003; Hamza, 2001; Milkis, 1984; Mogi et al., 1989; Singh et al., 2002). These changes suggest a possible existence of interaction between the lithosphere and the atmosphere in seismic zones prior to the earthquakes (e.g. Dey and Singh, 2003). Ground temperature changes, related to tectonic activity, has been shown in some tectonic environments. The changing of ground thermal parameters induced by fluid flow, which are associated with local deformation processes, can be considered as the most likely mechanism for seismo-thermal perturbation at shallow depths (Hamza, 2001). Here we conduct an investigation to explore the suitability of some ground thermal parameters as an earthquake precursor in the Alborz region.

\section{Data and method}

Heat is transferred through the ground slowly, as the ground is often a thermal conductor. The amplitude of a diurnal variation of soil temperatures decreases exponentially with the depth (Fig. 1). It is significant down to the soil depth of one meter for an annual surface temperature change due to the seasonal variation. Daily temperature variations at the surface are also substantially reduced and the typical efolding scale depth for this is about $0.15 \mathrm{~m}$ for rather dry soil (Arya, 1988). Therefore, the meteorological parameters affect mostly the near surface soil; however, the energy of earthquakes often affect the ground at the deeper part. As a result we consider the ground temperature variation at a one meter depth as a short time (about a few days) earthquake precursor. The Alborz region is selected because of: the high potential for seismic activities, the large number of active and seismic faults, the high density population and the adjacent cities near the active main faults (Fig. 2). The ground temperature value, down to one meter, during a 12 years period

Published by Copernicus Publications on behalf of the European Geosciences Union. 
Table 1. Temperature anomaly greater than 0.3 for all Alborz region earthquakes ( $>4$ Richter) during the time of study.

\begin{tabular}{cccccc}
\hline Date & Hour & Magnitude & City & $\begin{array}{c}\text { The meteorological } \\
\text { closest station }\end{array}$ & $\begin{array}{c}\text { Variation of ground } \\
\text { temperature }\left({ }^{\circ} \mathrm{C}\right)\end{array}$ \\
\hline 13 Jan 2003 & $16: 41: 45$ & 4.4 & Ardebil & Ardebil & 0.4 \\
12 May 1997 & $03: 51: 00$ & 4.6 & Ardebil & Ardebil & 0.4 \\
3 Dec 1998 & $18: 29: 48$ & 4.3 & Tehran & Doushantapeh & -0.3 \\
25 Feb 2002 & $14: 22: 10$ & 4.1 & Semnan & Semnan & 0.4 \\
9 Jun 1993 & $17: 33: 37$ & 4.7 & Semnan & Semnan & 0.3 \\
22 Jun 2002 & $21: 33: 36$ & 4.5 & Qazvin & Avaj & 0.3 \\
26 Nov 1999 & $04: 27: 22$ & 5 & Golestan & Gonbad & 0.3 \\
7 Jan 2004 & $04: 28: 18$ & 5.5 & Mazandaran & Siahbisheh & 0.3 \\
25 Apr 2002 & $17: 40: 19$ & 4.8 & Mazandaran & Babolsar & 0.3 \\
16 May 2001 & $07: 24: 29$ & 4 & Mazandaran & Qarakhil & 0.3 \\
9 Jan 1998 & $19: 06: 15$ & 4.6 & Mazandaran & Babolsar & 0.5 \\
3 Dec 1998 & $13: 13: 34$ & 4.3 & Tehran & Doushantapeh & -0.7 \\
\hline
\end{tabular}

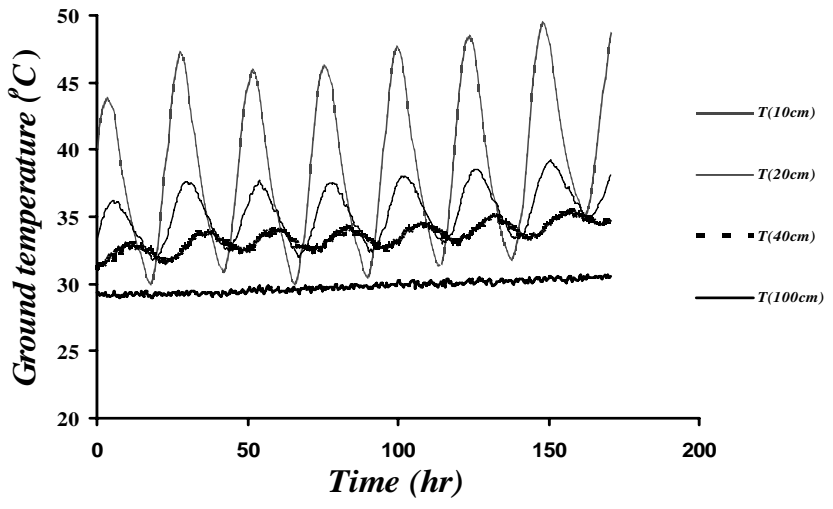

Fig. 1. Temperature records at depths: $10,20,40$, and $100 \mathrm{~cm}$ at Geophysics station 28 June 1995-11 July 1995.

(1992-2004) is analyzed to find out if there is a relation between temperature, thermal diffusivity, ground heat flux perturbations and earthquakes.

The ground temperature at a location is essentially given by the surface energy balance, which in turn depends on the radiation balance, atmospheric exchange processes in the immediate vicinity of the surface, the presence of vegetation, and thermal properties of the subsurface medium (Arya, 1988).

For identification of a thermal earthquake precursor, it is necessary to analyze more data such as earthquake specifications, ground temperature (at 03:00, 09:00, and 15:00 in UTC time), type, and some other thermal parameters of soil which are explained in detail as follows:

1. Earthquake specifications: such as magnitude, location, date and time of an earthquake in the Alborz region from 1992 to 2004 are received from the National Geosciences Database of Iran (NGDIR). Due to too many numbers of earthquakes that have occurred in the $\mathrm{Al}$ borz region and superabundant data, only the earthquakes with Richter 4 and above are considered, however we have only shown the earthquakes with a magnitude greater than 4 with a temperature anomaly equal and greater than 0.3 (Table 1).

2. Ground temperature: in this research, data of the ground temperature is from the Iran Meteorological Organization (http://www.irimet.net/). The temperature data istaken manually from this Organization. To study the soil temperature, the data from 50 weather stations in the Alborz region during 12 years from 1992 to 2004 is utilized (meteorological stations are scattered in the region for synoptic weather monitoring but instead we have used the ones that are near the earthquake faults) Ground temperatures were taken three times a day (at 03:00, 09:00 and 15:00 in UTC time), at the depth of 05, $10,20,30,50$ and $100 \mathrm{~cm}$. The nearest stations to the epicenter of the earthquakes were analyzed. The earthquake energy decreases with distance, in other words, the areas close to the epicenter have the most energy, hence; the ground temperatures of the closest stations to the epicenter are analyzed. However, thermal surface changes as a result of seismic activities prior to an earthquake, can lead to the movement of water, gas and etc. (Hamza, 2001). This may indirectly change the thermal state close to the surface. This is the main factor for thermal perturbations that we are looking into.

3. Type of soil: This data is received from NGDIR. The type of soil affects small and big changes in ground temperature. Therefore, this data was considered in our analysis. 


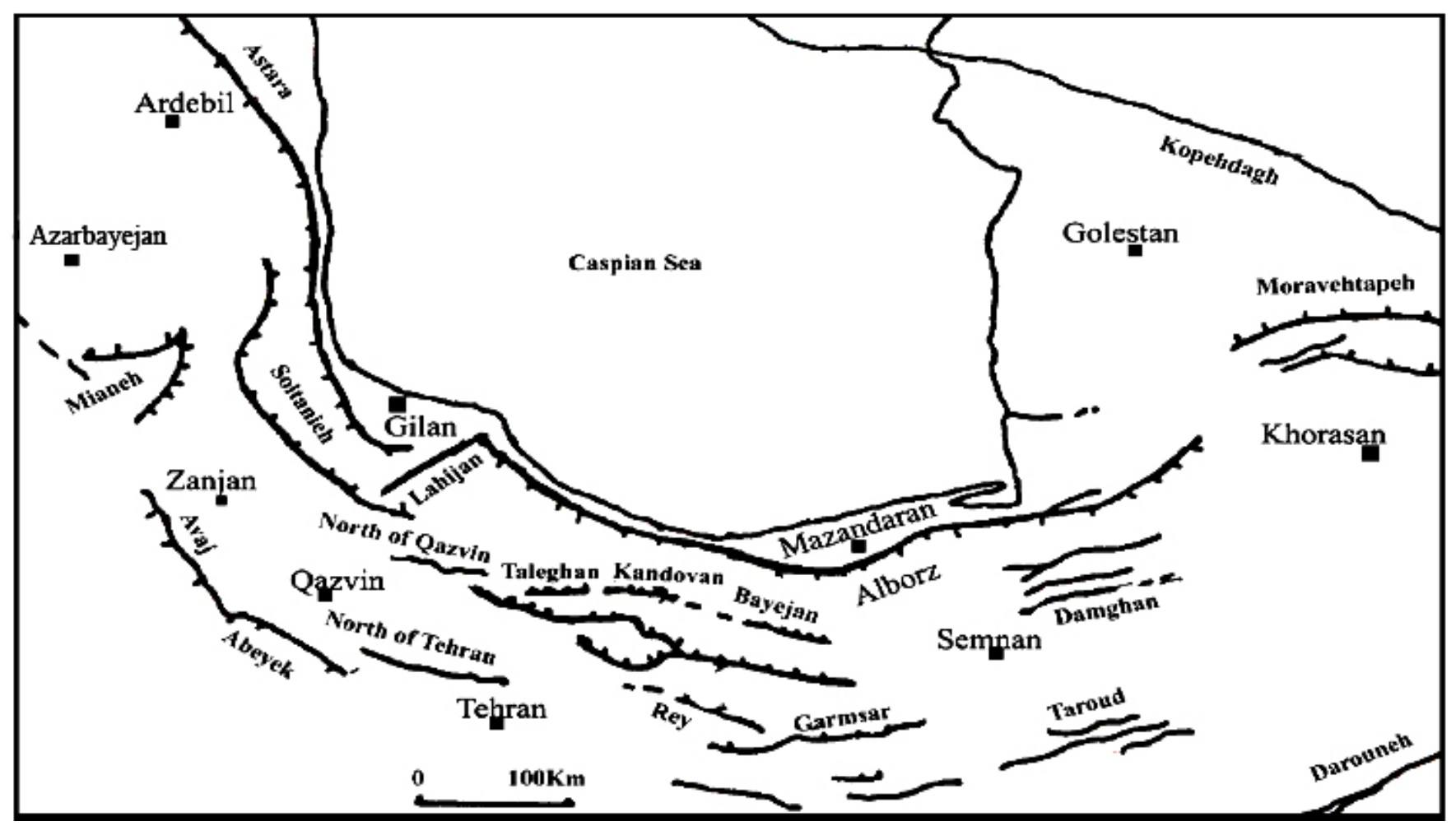

Fig. 2. Active main faults $(\widetilde{a})$ and location of provinces in Alborz region ( $\mathbf{\square}$ ).

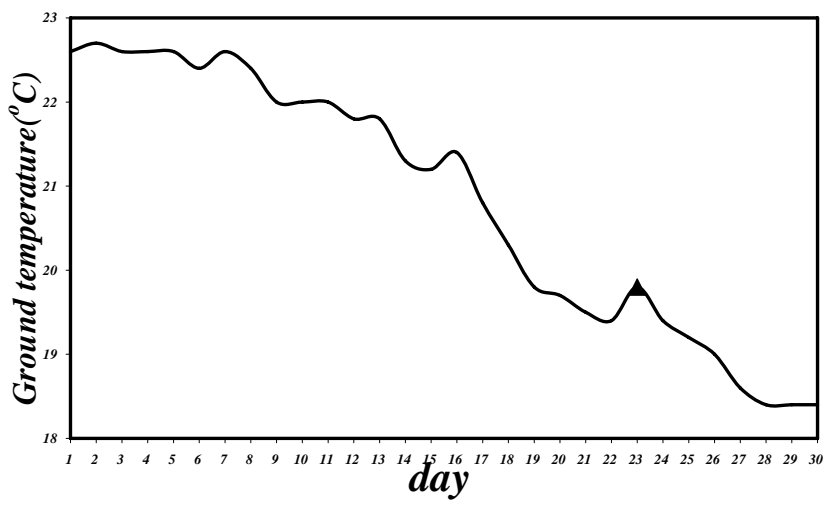

Fig. 3. Ground temperature in earthquake of Semnan for 30 days (23 November 1995), M=4.0 Richter.

\section{Results and discussion}

Changes in ground thermal parameters at the surface and shallow depths depend on many factors including intensity of solar radiation, physical properties of soil, soil moisture content (that are dependent on the time during the year) and probably tectonic activities. Therefore, for its probable changes before the earthquakes, ground temperature-time diagrams for different months during the 12 years are analyzed separately and the time of the earthquakes in the months are

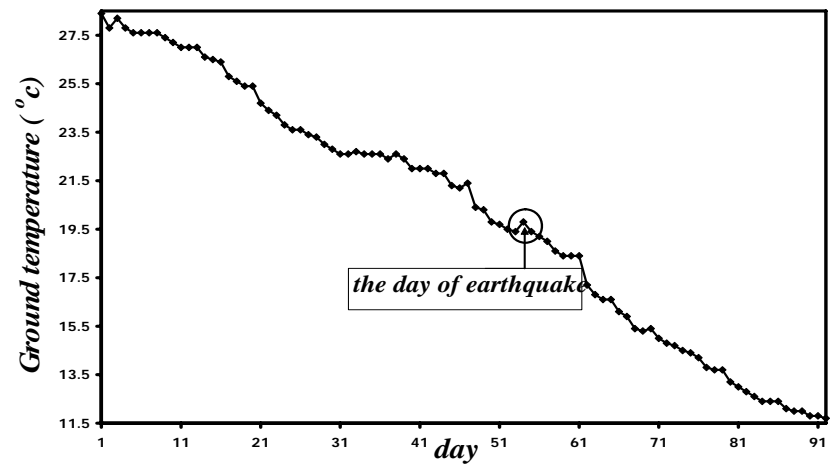

Fig. 4. Ground temperature in earthquake of Semnan for 3 mounth (from October to December) (23 November 1995), M=4.0 Richter.

demonstrated on the diagrams (Figs. 3 and 4). Typical temperature anomalies observed prior to the earthquakes is about $0.4^{\circ} \mathrm{C}$ (Figs. 3-10). The time of the maximum and the minimum ground temperature as well as the diurnal range, are of considerable interest. Because, we all know, on clear days, the maximum ground temperature is reached typically an hour or two after the time of maximum insulation, while the minimum temperature is reached in the early morning. But our investigations showed that the maximum and minimum ground temperatures occurred some hours before the earthquakes in Alborz. For example, the minimum temperature 


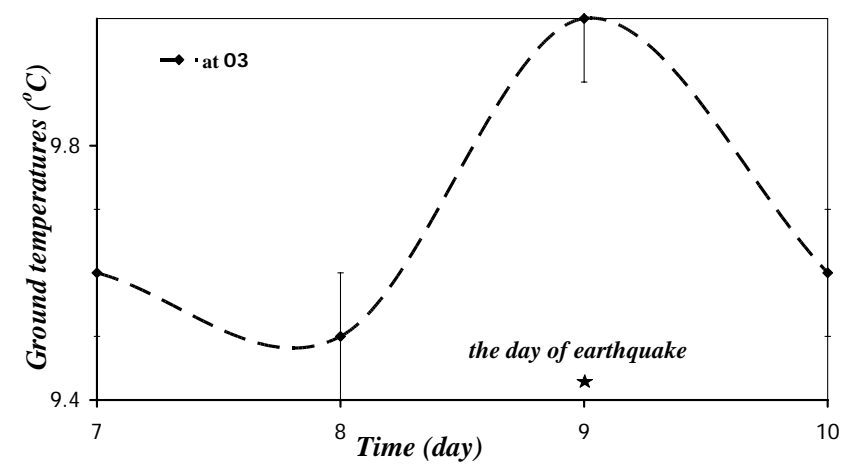

Fig. 5. Ground temperature in earthquake of Babolsar (9 January 1998), $M=4.6$ Richter.

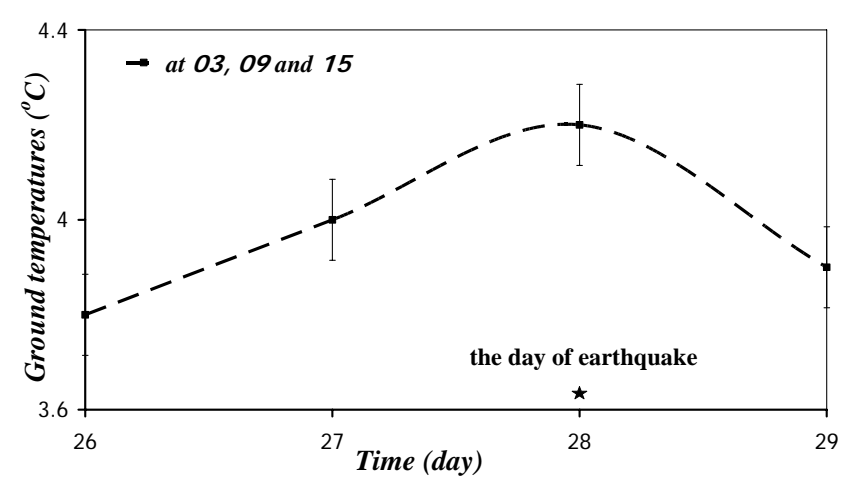

Fig. 6. Ground temperature in earthquake of Ardebil (28 February 1997), $M=4.2$ Richter.

does not reach exactly early morning in the Semnan earthquake on 25 February 2002 (Table 1). Ground temperature values have unusually increased typically around $0.4{ }^{\circ} \mathrm{C}$, near the plate of fault, before the occurrence of all the earthquakes in the Alborz region in January, February, April, may, June, July and November (e.g. Figs. 3-9) during a period of 12 years. However, it decreases typically around $0.4{ }^{\circ} \mathrm{C}$ in August, October and December (e.g., Fig. 10) during 19922004.

Soil moisture, groundwater temperature and the peizometric surface can be changed by the build-up of tectonic deformation in a fault zone (Buntebarth et al., 1999; Hamza, 2001; Kitagawa et al., 1996; Milkis, 1984; Mogi et al., 1989; Rynn and Scholz, 1978; Shimamura et al., 1985). Groundwater can be moved easier in an aquifer layer (Lutgens and Tarbuck, 1989). Thermal energy flux can be transferred to the surface as a result of the changes of peizometric surface from the earthquake activity (Hamza, 2001). Hence, the ground temperature could be changed due to tectonic activity. But the small and big changes in ground temperature can be related to the type of the fault, type of the soil and the groundwater source. Fine-textured soils (e.g., clay) have greater heat capacities as compared to coarse soils (e.g., sand). The

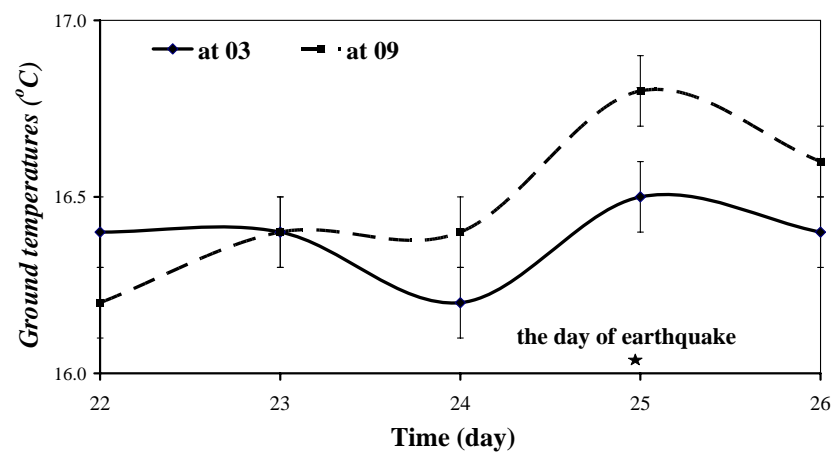

Fig. 7. Ground temperature in earthquake of Babolsar (25 April 2002), $M=4.8$ Richter.

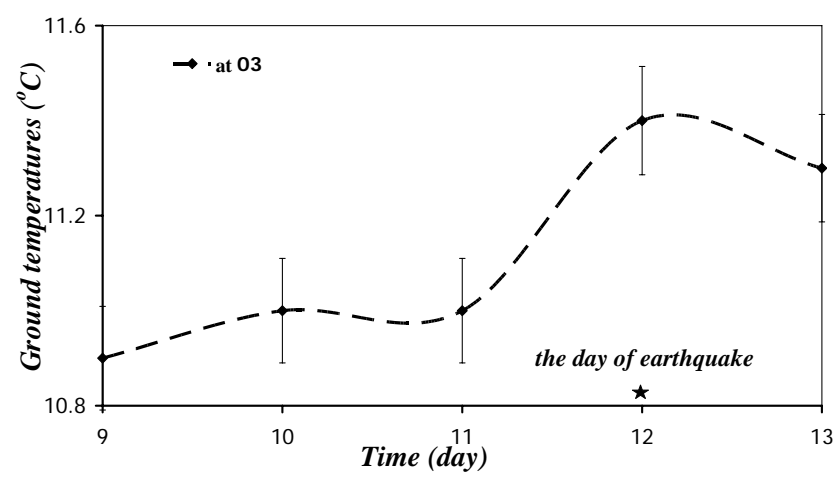

Fig. 8. Ground temperature in earthquake of Ardebil (12 May 1997), $M=4.6$ Richter.

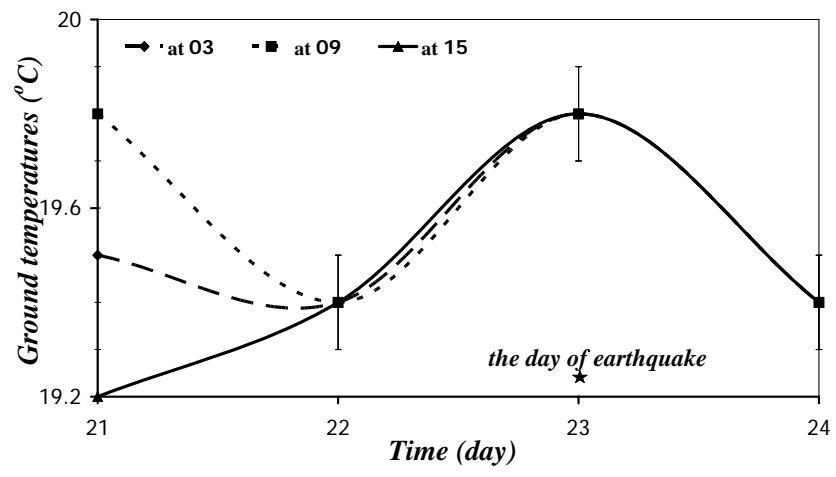

Fig. 9. Ground temperature in earthquake of Semnan (23 November 1995), $M=4.0$ Richter.

presence of moisture in the ground greatly increases heat capacity and thermal conductivity of the soil. In addition, our studies showed that in Alborz region during 12 years, there were temperature anomalies (e.g. Figs. 3-10). Therefore, the change of ground temperature could be an earthquake precursor in the Alborz region.

Thermal diffusivity and ground heat flux are also changed some hours before earthquakes. These changes were positive 


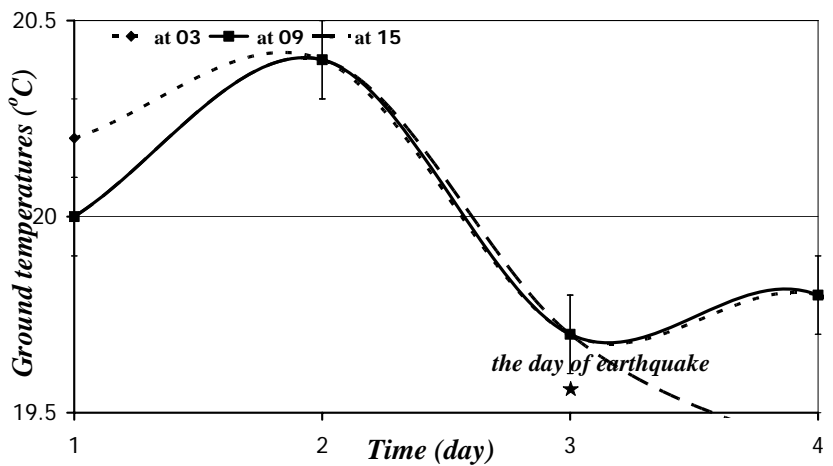

Fig. 10. Ground temperature in earthquake of Tehran (3 December 1998), $M=4.6$ Richter.

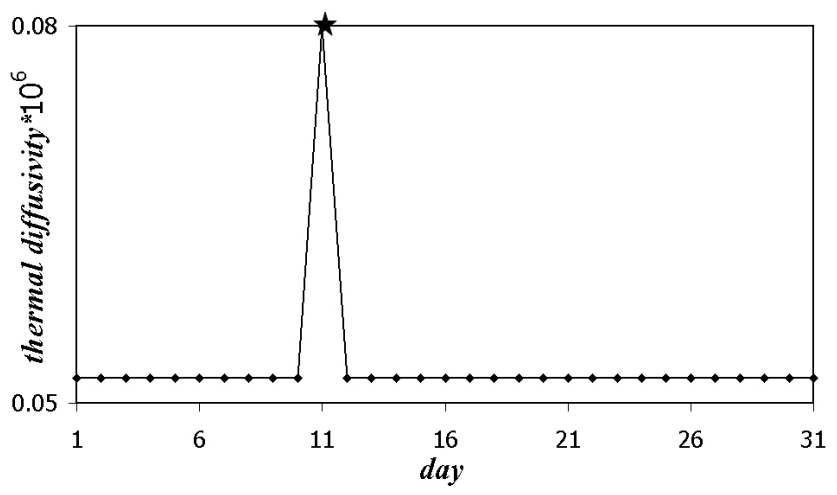

Fig. 11. Thermal diffusivity in earthquake of Garmsar (11 January 2003), $M=5.8$ Richter.

far away from the sea (Figs. 11 and 12) and negative near coastal regions (Figs. 13 and 14), indicating changes of soil moisture content. Since the ground heat flux is related to the energy exchange between the earth's surface and subsurface, this interaction might be increased during the earthquake activities in the area. According to Figs. 11 and 13, thermal diffusivity of the ground seems to be constant before and after the earthquakes, but not close to the time of earthquakes. The addition of water to dry soil enhances its heat capacity and conductivity markedly because it replaces the air (a poor heat conductor) in the pore space (Arya, 2001). The change of soil moisture content before the earthquakes with abnormal heat flux in the atmosphere, was also reported by others (such as, Dey and Singh, 2003). As a result, earthquakes can increase the soil moisture content significantly due to the changes in the ground water level. Changes of water level may lead to an exchange of air between below the ground surface and above the surface, and hence the changes of thermal behavior near the surface zone.

Therefore, changes in ground temperature, thermal diffusivity and ground heat flux could be used as earthquake precursors.

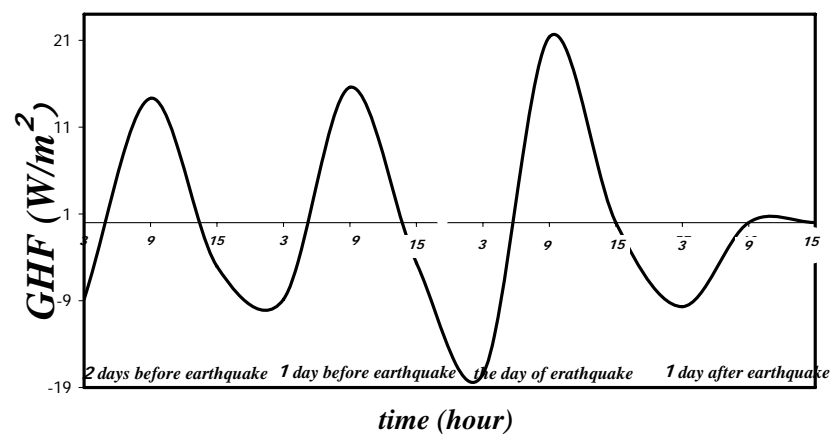

Fig. 12. Ground heat flux (GHF) in earthquake of Garmsar (11 January 2003), M=5.8 Richter.

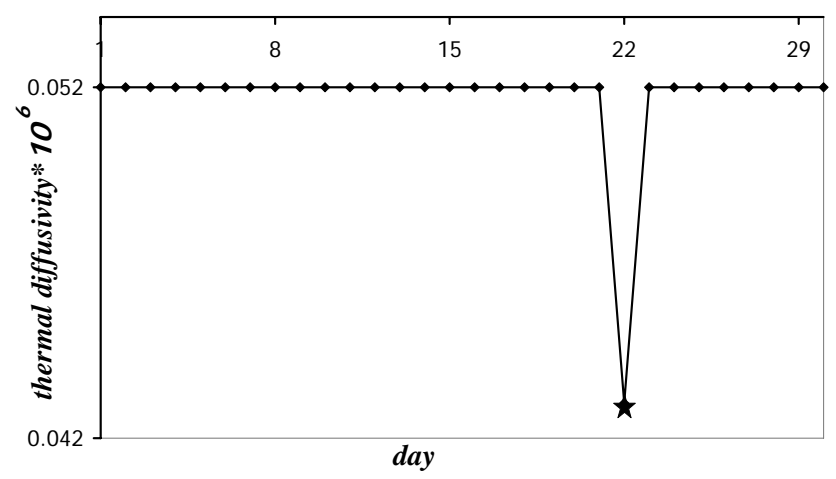

Fig. 13. Thermal diffusivity in earthquake of Ghaemshahr (22 September 1992), M=5.1 Richter.

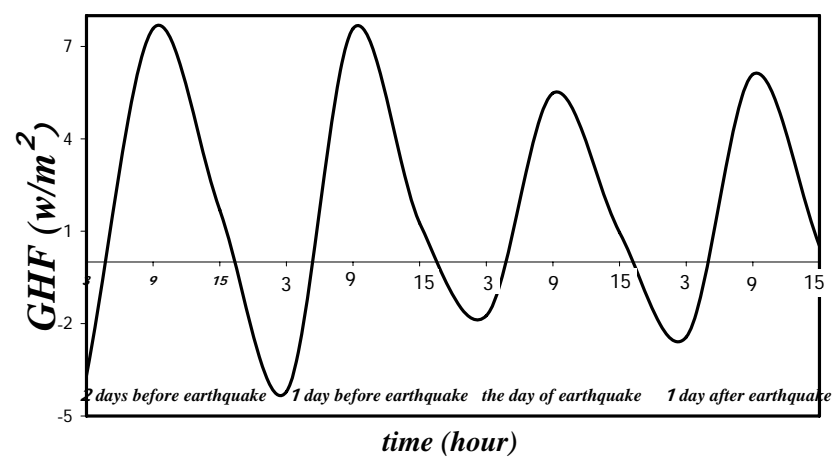

Fig. 14. Ground heat flux (GHF) in earthquake of Ghaemshahr (22 September 1992), M=5.1 Richter.

\section{Conclusions}

We have carried out an analysis of ground thermal parameters for more than 70 earthquakes throughout the coastal, mountainous and desert regions of the Alborz region during a period of 12 years. This analysis has shown some anomalous behavior in the ground temperature, ground thermal diffusivity and ground heat flux in tectonically active areas some hours prior to the earthquakes. The anomalies of ground 
thermal parameters in various earthquakes, show a systematic pattern before the events which might be assumed as precursors for imminent earthquake in the Alborz region.

In this study, we have used pre-existing data that were measured for meteorological monitoring. However, the enhanced spatial and temporal resolution of the sensors provide more accurate ground heat flux information over the tectonically active areas, hence the installation of an observatory system, for monitoring temperatures of the subsurfaces in zones of active faults, can contribute a great deal to the existing database.

Acknowledgements. The authors would like to thank the Iranian Meteorological Organization, Geological Survey of Iran and Iranian Seismological Center of the Institute of Geophysics for providing the data. R. Singh and D. Shanker are thanked for their constructive comments. We would like to thank Arsalan Fattahi for upgrading the general English of the manuscript.

Edited by: M. E. Contadakis

Reviewed by: R. Singh and D. Shanker

\section{References}

Arya, S. P.: Introduction to Micrometeorology: International Geophysics Series, 79, Academic press, 420 pp., 2001.

Buntebarth, G., Ishankulive, G. A., and Belikov, V. M.: Anomalous variations of the temperature and out flow rate of groundwater in the Kopetdagh Seismoactive region, Turkmenistan, in: Microtemperature Signals of the Earth' Crust: Papierflieger, edited by: Buntebarth, G., Claausthal-Zellerfeld, Germany, pp. 138$141,1999$.

Cervone, G., Singh, R. P., Kafatos, M., and Yu, C.: Wavelet maxima curves of surface latent heat flux anomalies associated with Indian earthquakes, Nat. Hazards Earth Syst. Sci., 5, 87-99, 2005, http://www.nat-hazards-earth-syst-sci.net/5/87/2005/.

Darvishzadeh, A.: Geological Of Iran, Sepehr press, Tehran, Iran, 350 pp., 1992.

Dey, S. and Singh, R. P.: Surface latent heat flux as an earthquake precursor, Nat. Hazards Earth Syst. Sci., 3, 749-755, 2003, http://www.nat-hazards-earth-syst-sci.net/3/749/2003/.

Dey, S., Sarker, S., and Singh, R. P.: Anomalous changes in column water vapor after Gujarat earthquake, Adv. Space Res., 2003.

Esposito, E., Pece, R., Porfido, S., and Tranfaglia, G.: Hydrological anomalies connected to earthquakes in southern Apennines (Italy), Nat. Hazards Earth Syst. Sci., 1, 137-144, 2001, http://www.nat-hazards-earth-syst-sci.net/1/137/2001/.

Hamza, V. M.: Tectonic leakage of fault bounded aquifers subject to non-isothermal recharge: a mechanism generating thermal: Physics of the Earth and Planetary Interiors, 126, pp. 163-177, 2001.
Hayakawa, M., Fujinawa, Y., Evison, F. F., Shapiro, V. A., Varotsos, P., Fraser-Smith, A. C., Molchanov, O. A., Pokhotelov, O. A., Enomoto, Y., and Schloessin, H. H.: What is the future direction of investigation on electromagnetic phenomena related to earthquake prediction, Terra Sci. pub. Comp., Tokyo, 667-677, 1994.

Hayakawa, M.: Atmospheric and Ionosphere Electromagnetic Phenomena Associated with Earthquakes, Terra Sci., Publ. Comp., Tokyo, p. 995, 1999.

Hayakawa, M., Shvets, A. V., and Shinko Maekawa, S.: Subionospheric LF monitoring of ionospheric perturbations prior to the Tokachi-oki earthquake and a possible mechanism of lithosphere-ionosphere coupling, Phys. Chem. Earth, 29, 617625, 2004.

Iran meteorological organization: www.irimet.net, last access: March 2010.

Iran geological organization: www.ngdir.ir, last access: March 2010 .

Kitagawa, Y., Koizumi, N., and Tsuskuda, T.: Comparison of post-seismic groundwater temperature changes with earthquakeinduced volumetric strain release: Yudani hot spring, Japan, Geophys. Res. Lett., 23(22), 3147-3150, 1996.

Lutgens, F. K. and Tarbuck, E. J.: Essentials of Geology: Prentice Hall, 480, pp., 1989.

Milkis, M. R.: Hydrogeological and hydometeorological precursors of Ashkabad catastrophic earthquake, in: Is USSR Rept.: Earth Sci. (JPRS-USE-84-004) p 56-57 (SEE N84-27177 17-42) Transl. into ENGLISH from Dokl. Akad. Nauk SSSR (Moscow), v. 273, pp. 1091-1094, 1984.

Mogi, K., Mochizuki, H., and Kurokawa, Y.: Temperature changes in an artesian spring at Usami in the Izu peninsula (Japan) and their relation to earthquakes, Tectonophysics, 159, 95-108, 1989.

Molchanov, O. A., Pokhotelov, O. A., Enomoto, Y., and Schloessin, H. H.: What is the future direction of investigation on electromagnetic phenomena related to earthquake prediction, Terra Sci. pub. Comp., Tokyo, 667-677, 1994.

Pulinets, S.: Ionospheric Precursors of Earthquakes; Recent Advances in Theory and Practical Applications, J. Atmos. SolarTerr. Phys., 65(2003), 1337-1347, 2004.

Rynn, S. M. W. and Scholz, C. H.: Seismotectonics of the Arthur's Pass region, South Island, New Zealand, Bull. Seismol. Soc. Am., 89, 1373-1388, 1978.

Shimamura, H., Ino, M., Hikawa, H., and Iwasaki, T.: Groundwater micro-temperature in earthquake regions, Pure Appl. Geophys. 122, 933-946, 1985.

Shvets, A. V., Hayakawa, M., Molchanov, O. A., and Ando, Y.: A study of ionosphere response to regional seismic activity by VLF radio sounding, Phys. Chem. Earth, 29, 627-637, 2004.

Singh, R. P., Bhoi, S., and Sahoo, A. K.: Changes observed on land and ocean after Gujarat earthquake 26 January 2001 using IRS data, Int. J. Remot., 23(16), 3123-3128, 2002.

Uyeda, S., Nagao, T., Orihara, Y., Yamaguchi, T., and Takahashi, I.: Geoelectric potential changes: Possible precursors to earthquakes in Japan, Proc. Nat. Acad. Sci., 97, 4561-4566, 2000. 